\title{
Community acquired pneumonia: aetiology and usefulness of severity criteria on admission
}

A M Neill, I R Martin, R Weir, R Anderson, A Chereshsky, M J Epton, R Jackson, M Schousboe, C Frampton, S Hutton, S T Chambers, G I Town
The Canterbury Respiratory Research Group, Christchurch School of Medicine, P O Box 4345, Christchurch,

New Zealand

A $M$ Neill

I R Martin

$\mathrm{R}$ Anderson

M J Epton

G I Town

Microbiology

Laboratory,

Canterbury Health

Laboratories

R Weir

M Schousboe

ESR: Health,

Communicable

Diseases Centre,

Porrirua

A Chereshsky

Department of

Radiology, Canterbury

Health

R Jackson

Department of

Medicine,

Christchurch School

of Medicine

C Frampton

Department of

Pathology,

Christchurch School

of Medicine

$S$ T Chamber

Menzies School of

Health Research,

Darwin, Australia

$S$ Hutton

Correspondence to:

Dr G I Town.

Received 5 December 1995

Returned to authors

12 February 1996

Revised version received

15 June 1996

Accepted for publication

27 June 1996
Abstract

Background - Community acquired pneumonia remains an important cause of hospital admission and carries an appreciable mortality. Criteria for the assessment of severity during admission have been developed by the British Thoracic Society (BTS). A study was performed to determine the sensitivity and specificity of a severity rule based on a modification of the BTS prognostic rules applied on admission, to compare severity as assessed by medical staff with the modified rule, and to determine the microbiological cause of community acquired pneumonia in Christchurch.

Methods - A 12 month study of all adults admitted to Christchurch Hospital with community acquired pneumonia was undertaken. Three hundred and sixteen consecutive patients with suspected community acquired pneumonia were screened for inclusion. Variables obtained from the history, examination, investigations, and initial treatment were examined for association with mortality.

Results - Two hundred and fifty five patients met the inclusion criteria. Their mean age was 58 years (range 18-97). A microbiological diagnosis was made in 181 cases $(71 \%)$, Streptococcus pneumonia (39\%), Mycoplasma pneumoniae (16\%), Legionella species (11\%), and Haemophilus influenzae (11\%) being the most commonly identified organisms. Patients had a 36-fold increased risk of death if any two of the following were present on admission: respiratory rate $\geq 30 / \mathrm{min}$, diastolic $\mathrm{BP} \leq 60 \mathrm{~mm} \mathrm{Hg}$, urea $>7 \mathrm{mmol} / 1$, or confusion. The severity rule identified 19 of the 20 patients who died and six of eight patients admitted to the intensive care unit as having life threatening community acquired pneumonia. The sensitivity of the modified rule for predicting death was 0.95 and the specificity 0.71 . In 47 cases $(21 \%)$ the clinical team appeared to underestimate the severity of the illness.

Conclusions - The organisms responsible for community acquired pneumonia in Christchurch are similar to those reported from other centres except for Legionella species which were more common than in most studies. The modification of the BTS prognostic rules applied as a severity in- dicator at admission performed well and could be incorporated into management guidelines.

(Thorax 1996;51:1010-1016)

Keywords: community acquired pneumonia, severity assessment, mortality, aetiology.

Community acquired pneumonia is the most common serious infection encountered in medical practice with $1-10 \%$ of patients requiring admission to hospital. The mortality rate of patients admitted is significant, ranging from $6.7 \%$ to $18 \%$. $^{1}$ It has been recommended that the choice of initial antibiotic be guided primarily by the severity of illness ${ }^{23}$ together with local information about the range of organisms responsible. This rationale is derived from studies showing that the clinical ${ }^{45}$ and radiographic features ${ }^{67}$ of the common causes of pneumonia are not sufficiently specific to predict the microbiological cause accurately.

The range of micro-organisms reported as being responsible for community acquired pneumonia varies between studies and depends on the patient population studied, the extent of laboratory investigations, and the microbiological techniques employed. In 1987 the Research Committee of the British Thoracic Society (BTS) and Public Health Laboratory Services published a comprehensive study of community acquired pneumonia. ${ }^{1}$ Of the 453 patients enrolled (aged 15-74 years) a microbiological diagnosis was established in $67 \%$ of cases. Streptococcus pneumoniae (34\%), Mycoplasma pneumoniae (18\%), and influenza A virus (7\%) were the commonest micro-organisms detected. Legionella infection appeared to be uncommon $(2 \%)$. The only previous study in New Zealand reported a microbiological diagnosis in $72 \%$ of the 92 patients enrolled and detected a similar range of organisms to the BTS series. ${ }^{8}$

Multivariate analysis of prognostic factors associated with death from community acquired pneumonia in the BTS study led to the development of three prognostic rules based on variables obtained either at presentation to hospital or during admission (table 1). ${ }^{1}$ These rules have been validated by others who have emphasised their potential use in severity assessment and triage on presentation to hospital. ${ }^{9}$ We elected to use modified criteria which 
Table 1 British Thoracic Society discriminant rules for prediction of mortality ${ }^{I}$

\begin{tabular}{|c|c|}
\hline Rule & \\
\hline Rule 1 & $\begin{array}{l}\text { Two of three criteria } \\
\text { Respiratory rate } \geq 30 / \mathrm{min} \\
\text { Diastolic blood pressure } \leq 60 \mathrm{~mm} \mathrm{Hg} \\
\text { Blood urea }>7.0 \mathrm{mmol} / 1 \text { (during admission) }\end{array}$ \\
\hline Rule 2 & $\begin{array}{l}\text { Two of three criteria } \\
\text { Respiratory rate } \geq 30 / \mathrm{min} \\
\text { Diastolic blood pressure } \leq 60 \mathrm{~mm} \mathrm{Hg} \\
\text { Confusion }\end{array}$ \\
\hline Rule 3 & $\begin{array}{l}\text { Three of four criteria } \\
\text { Confusion } \\
\mathrm{PaO}_{2} \leq 6.6 \mathrm{kPa} \\
\text { White blood count } \leq 10 \times 10^{9} / 1 \text { or lymphocytes } \\
\leq 1 \times 10^{9} / 1 \\
\text { Blood urea } \geq 7.0 \mathrm{mmol} / 1 \text { (during admission) }\end{array}$ \\
\hline $\begin{array}{l}\text { Modified } \\
\text { BTS rule }\end{array}$ & $\begin{array}{l}\text { Two or more of four criteria on admission } \\
\text { Respiratory rate } \geq 30 / \mathrm{min} \\
\text { Diastolic blood pressure } \leq 60 \mathrm{~mm} \mathrm{Hg} \\
\text { Blood urea }>7.0 \mathrm{mmol} / 1 \\
\text { Confusion* }\end{array}$ \\
\hline
\end{tabular}

* Where a Mental Status Quotient (MSQ) was recorded confusion was defined as an MSQ $\leq 8 .{ }^{13}$

simplified the three rules into a single rule which could be applied on admission.

A 12 month study of adults admitted to Christchurch Hospital (a 600 bed acute facility serving a population of 350000 ) with community acquired pneumonia was performed to assess the microbiological cause, severity, and outcome. We prospectively studied a severity rule (based on BTS criteria) applied on admission by comparing it with a clinical severity assessment performed by medical staff. Our hypothesis was that the use of the modified rule would improve the identification of those patients at increased risk of dying or requiring admission to the intensive care unit. We also conducted a multivariate analysis of data obtained at admission to determine which, if any, additional variables might improve the prediction of mortality.

\section{Methods}

All adults admitted to Christchurch Hospital over a 12 month period (July 1992 to July 1993) were screened for possible inclusion in the study. The inclusion and exclusion criteria were based on those used in the original BTS study. ${ }^{1}$ Pneumonia was defined as an acute illness with radiographic pulmonary shadowing which was at least segmental or present in one lobe, and was neither pre-existing nor of other known cause. Patients were excluded when pneumonia was not the main reason for admission or was an expected terminal event, and when the pneumonia was associated with bronchial obstruction, bronchiectasis, or known tuberculosis. Patients with severe immunosuppression - neutropenia, AIDS, or receiving cancer chemotherapy - were excluded. Those with less profound immunosuppression on account of co-existing illness (renal failure, diabetes, liver impairment, alcoholism) or prolonged treatment with prednisone $(\geq 7.5 \mathrm{mg} /$ day $)$, methotrexate, or cyclosporin were included.

All chest radiographs were reviewed by a radiologist ( $R J)$ to confirm radiological entry criteria and to document the extent of con- solidation and presence of any additional abnormalities.

Enrolment was by resident medical staff who collected clinical data, completed an investigation check list, and recorded a severity assessment (mild, moderate or severe) based on their usual clinical criteria. The clinical team was responsible for all aspects of patient care while in hospital, including choice of antibiotic.

The clinical severity assessment performed by the attending doctors was prospectively compared with a severity assessment based on a modification of the first two BTS prognostic rules (table 1). We defined severe pneumonia as occurring when two or more variables (respiratory rate $\geq 30 / \mathrm{min}$, diastolic $B P \leq 60 \mathrm{~mm}$ $\mathrm{Hg}$, a blood urea concentration of $>7.0 \mathrm{mmol} /$ 1 , and confusion) were present at the time of admission.

\section{INVESTIGATIONS}

A chest radiograph was obtained on admission and at six weeks. Venous blood was sampled for urea, creatinine, electrolytes, albumin, calcium, and liver function tests (aspartate aminotransferase (AST), ALP, bilirubin). Arterial blood gas tensions were measured in most cases. Nasopharyngeal and throat swabs, sputum, blood and urine specimens were obtained on admission and processed according to standard protocols. The criteria used for the laboratory diagnosis of infection were the same as those used in the BTS study. ${ }^{1}$

\section{OUTCOME}

Outcome was assessed by measuring survival to hospital discharge, duration of hospital stay, the development of any clinically relevant complications, whether the patient had returned to the usual level of activity, and the extent of radiographic resolution six weeks after admission. Initial antibiotic treatment, oxygen requirements, and the volume of intravenous fluids received during the first 24 hours were also recorded. A physician (AN) who was blind to the outcome retrospectively classified comorbidity into three categories based on past medical history. ${ }^{10}$

DATA PROCESSING AND STATISTICAL METHODS Data were entered onto a desk top computer using EPI INFO (version 5.01, 1990). Seventy one independent variables obtained from the history, physical examination, laboratory tests, and initial treatment were examined for association with mortality and duration of hospital stay. The association between categorical variables and survival was assessed by $\chi^{2}$ (or two tailed Fisher's exact test when the expected cell frequencies were less than five). Results are reported as significant at $\mathrm{p}<0.05$ or by relative risk with $95 \%$ confidence intervals. ANOVA was used to assess differences between means for normally distributed data ${ }^{11}$ and Kruskal-Wallis one way analysis of variance for non-parametric data. ${ }^{12}$ 
Table 2 Demographic and clinical features according to outcome

\begin{tabular}{|c|c|c|c|c|c|}
\hline Variable & $\begin{array}{l}\text { No. } \\
\text { recorded }\end{array}$ & $\begin{array}{l}\text { Entire group } \\
(n=255)\end{array}$ & $\begin{array}{l}\text { Survived } \\
(n=235)\end{array}$ & $\begin{array}{l}\text { Died } \\
(n=20)\end{array}$ & $p$ value* \\
\hline \multicolumn{6}{|l|}{ Demographics and history: } \\
\hline Microbiological diagnosis (\%) & 255 & 71 & 72 & 65 & NS \\
\hline Age (years) & 255 & $58(22)$ & $57(22)$ & $78(11)$ & $<0.001$ \\
\hline Male sex $(\%)$ & 255 & 55 & 50 & 70 & NS \\
\hline Duration of stay (days) & 255 & $8.5(7.8)$ & $8.6(7.6)$ & $7.4(9.4)$ & NS \\
\hline Smoker $(\%)$ & 254 & 70 & 70 & 80 & NS \\
\hline Any chronic illness (\%)** & 255 & 60 & 58 & 90 & 0.005 \\
\hline Co-morbidity score*** & 255 & & & & \\
\hline $1(\%)$ & & 46 & 49 & 10 & \\
\hline $2(\%)$ & & 49 & 46 & 85 & $<0.001 \dagger$ \\
\hline $3(\%)$ & & 5 & 5 & 5 & \\
\hline Prior antibiotic (\%) & 255 & 40 & 42 & 20 & 0.05 \\
\hline \multicolumn{6}{|l|}{ Examination findings: } \\
\hline Temperature $\left({ }^{\circ} \mathrm{C}\right)$ & 254 & $37.7(1.1)$ & $37.8(1.0)$ & $36.9(1.4)$ & 0.008 \\
\hline Pulse rate (bpm) & 255 & $99(18)$ & $98(17)$ & $113(20)$ & $<0.001$ \\
\hline Respiratory rate (breaths/min) & 251 & $26(8)$ & $25(7)$ & $33(7)$ & $<0.001$ \\
\hline Diastolic BP (mm Hg) & 255 & 72 (13) & 73 (13) & $66(15)$ & 0.01 \\
\hline Confusion (\%) & 255 & 16 & 13 & 50 & $<0.001$ \\
\hline Reduced peripheral perfusion (\%) & 245 & 12 & 8 & 61 & $<0.001$ \\
\hline JVP not visible (\%) & 250 & 20 & 18 & 40 & $<0.001$ \\
\hline MSQ $\ddagger$ & 212 & & & & \\
\hline 9 or 10 & & 83 & 86 & 41 & \\
\hline 6,7 or 8 & & 9 & 9 & 12 & \\
\hline Less than 6 & & 8.5 & 5 & 47 & $<0.001$ \\
\hline
\end{tabular}

Values are mean $(\mathrm{SD})$ or percentages.

* Statistical tests detailed in the methodology section. Significance value for comparison between those who survived and those who died.

** Disorders include COPD, asthma, cardiac failure, cancer, alcoholism, cirrhosis, chronic renal failure.

*** Co-morbidity score $^{10}: 1=$ no important chronic illness; $2=$ moderate/severe disease of heart, lungs, GI tract; $3=$ any cancer (except skin), end stage renal/liver disease, HIV.

+ Difference between a score of 1 compared with 2 or 3 .

$\neq$ Mental Status Quotient.

Stepwise logistic regression was used to assess the relative importance of variables that showed a significant $(\mathrm{p}<0.05)$ univariate association with mortality. Two logistic regression models were used. In model A age was forced into the model because of its importance in previous studies of outcome of pneumonia. In model B the modified BTS score was forced into the model to determine which additional variables would significantly improve the prediction of mortality. Where additional variables were used, cut off points were selected which maximised the sensitivity and positive predictive value.

The modified BTS rule was compared with the three original BTS rules for relative risk, sensitivity, specificity, positive and negative predictive values.

\section{Results}

During the 12 month study period 316 patients were screened for possible inclusion. Clinical and radiographic review resulted in 55 exclusions. There were six patients who satisfied the entry criteria but in whom consent could not be obtained (all but one of these patients survived to hospital discharge). Two hundred and fifty five patients remained for analysis. The mean age was 58 years (range 18-97 years) and $55 \%$ were men. Twenty patients $(7.8 \%)$ died in hospital, and a further four patients died following discharge and prior to the six week follow up visit. Complete follow up data were obtained in $200(87 \%)$ of the survivors.

\section{HISTORY}

The mean duration of symptoms prior to admission was 7.7 days (table 2$)$. Cough $(88 \%)$, sputum production $(64 \%)$, and chest pain
(57\%) were the most commonly reported respiratory symptoms. A significant proportion reported headache $(34 \%)$, myalgia $(26 \%)$, and arthralgia (19\%). Abdominal pain occurred in $13 \%$, resulting in admission to a surgical ward in two cases. Underlying illness was present in the majority, including chronic obstructive pulmonary disease $(33 \%)$ and cardiac failure (18\%). According to our criteria, immunosuppression was present in $24 \%$. On admission $103(40 \%)$ patients were taking oral antibiotics of which amoxycillin-clavulanate $(50 \%)$ and erythromycin $(18 \%)$ were the most frequently prescribed.

PHYSICAL FINDINGS ON ADMISSION

A temperature higher than $37.5^{\circ} \mathrm{C}$ was recorded in 135 patients (53\%), tachycardia (pulse $\geq 100 / \mathrm{min}$ ) in $133(52 \%)$, and tachypnoea (respiratory rate $\geq 30 / \mathrm{min}$ ) in $74(29 \%)$. A mental state quotient (MSQ) ${ }^{13}$ was obtained in $212(83 \%)$. Systolic hypotension (BP $<100 \mathrm{~mm} \mathrm{Hg}$ ) was noted in $10 \%$ and diastolic hypotension ( $\mathrm{BP}<60 \mathrm{~mm} \mathrm{Hg}$ ) in $28 \%$. A low jugular venous pressure (JVP) was found in $20 \%$ and reduced peripheral perfusion (defined as cool peripheries with poor capillary return on blanching of a digit) in $12 \%$. The majority $(81 \%)$ had abnormal chest signs. Abdominal tenderness was noted in $13 \%$.

\section{INVESTIGATIONS}

A chest radiograph was obtained on admission in all but one patient who died in the emergency department and whose pneumonia was later confirmed by necropsy. Pulmonary shadowing was confined to a single lobe in $60 \%$. An arterial blood gas sample was obtained in 238 cases 
Table 3 Initial investigations and severity assessment according to outcome

\begin{tabular}{|c|c|c|c|c|c|}
\hline Investigation & $\begin{array}{l}\text { No. } \\
\text { recorded }\end{array}$ & $\begin{array}{l}\text { Entire group } \\
(n=255)\end{array}$ & $\begin{array}{l}\text { Survived } \\
(n=235)\end{array}$ & $\begin{array}{l}\text { Died } \\
(n=20)\end{array}$ & $p$ value $^{*}$ \\
\hline Blood gases: & 238 & & & & \\
\hline $\mathrm{pH}$ & & $7.44(0.06)$ & $7.44(0.05)$ & $7.37(0.1)$ & $<0.001$ \\
\hline $\mathrm{PaO}_{2}(\mathrm{kPa})^{* * *}$ & & $9.46(2.53)$ & $9.60(2.53)$ & $8.13(2.13)$ & 0.006 \\
\hline \multirow{2}{*}{\multicolumn{6}{|c|}{ Biochemistry and haematology: }} \\
\hline & & & & & \\
\hline Urea $(\mathrm{mmol} / \mathrm{l})$ & 247 & & $7.4(4.8)$ & $17.0(10.5)$ & $<0.001$ \\
\hline $\begin{array}{l}\text { Ast }(\text { mmoll/1) } \\
\text { White cell count }\left(10^{\circ} / 1\right)\end{array}$ & & $41(70)$ & $37(58)$ & & $<0.001$ \\
\hline \multirow{2}{*}{\multicolumn{6}{|c|}{ Radiographic findings: }} \\
\hline \multirow{2}{*}{\multicolumn{6}{|c|}{ Number of lobes involved: }} \\
\hline & & & & & \\
\hline One $(\%)$ & & 58 & & 47 & \\
\hline Two (\%) & & 30 & 29 & 31 & \\
\hline Three or more (\%) & & 12 & 12 & 21 & NS \\
\hline Bilateral consolidation & & 27 & 6 & 26 & NS \\
\hline Parapneumonic effusion (\%) & & 21 & 5 & 37 & NS \\
\hline \multicolumn{6}{|l|}{ Severity assessment: } \\
\hline Clinical severity assessment: & 227 & & & & \\
\hline $\begin{array}{l}\text { Mild (\%) } \\
\text { (1) }\end{array}$ & & 31 & 33 & 11 & \\
\hline Moderate (\%) & & 51 & 53 & 26 & \\
\hline Severe $(\%)$ & & 18 & 14 & 63 & $<0.001$ \\
\hline \multirow{2}{*}{$\begin{array}{l}\text { Modified BTS criteria: } \\
\text { Mild or moderate (\%) } \\
\text { Severe (\%) }\end{array}$} & 248 & 66 & 71 & 5 & \\
\hline & & 34 & 29 & 95 & $<0.001$ \\
\hline
\end{tabular}

Values are mean (SD) or percentages.

* Statistical tests detailed in the methodology section. Significance value for comparison between those who survived and those who died.

$* * 40 \%$ of patients on oxygen at the time of sampling.

(93\%) and hypercapnic ventilatory impairment $\left(\mathrm{PCO}_{2}>6.0 \mathrm{kPa}\right)$ was present in $29(12 \%)$ (table 3).

\section{MICROBIOLOGY}

A satisfactory sputum sample was obtained in $77 \%$ of cases (table 4 ). Obtaining a sputum sample significantly increased the likelihood of making a microbiological diagnosis $(p<0.001)$. A microbiological diagnosis was established in 181 cases $(71 \%)$. In 121 patients $(67 \%)$ this consisted of a single organism and in $60(33 \%)$ more than one organism was identified. Streptococcus pneumoniae was the most common diagnosis, found in 100 cases (39\%), followed by Mycoplasma pneumoniae in 41 (16\%), Haemophilus influenzae in 28 (11\%), and Legionella species in $27(11 \%)$.

\section{OUTCOME}

Two hundred and thirty five patients $(92 \%)$ survived to hospital discharge. Two hundred $(87 \%)$ of the 231 patients alive six weeks after

Table 4 Microbiological diagnosis*

\begin{tabular}{llll}
\hline Organism & Number & Percentage & Number of deaths\# \\
\hline Streptococcus pneumoniae & 100 & 39 & 7 \\
Mycoplasma pneumoniae & 41 & 16 & 2 \\
Legionella sp\#\#\# & 27 & 11 & 1 \\
Haemophilus influenzae & 28 & 11 & 1 \\
Influenza A & 12 & 5 & \\
Chlamydia pneumoniae & 8 & 3 & \\
Moraxella catarrhalis & 8 & 3 & \\
Staphlococcus aureus & 7 & 3 & 1 \\
Enterobacteriaceae & 4 & 2 & 1 \\
Pseudomonas sp & 3 & 1 & 3 \\
Others** & 13 & 5 &
\end{tabular}

* Criteria for diagnosis as in BTS study. ${ }^{1} 121$ patients had a single organism identified, 50 two organisms, 9 three organisms, and 1 four organisms.

** Rhinovirus (2), RSV (1), para-influenza 3 (1), varicella zoster (1), Pasteurella multocidia (1) group C streptococcus (1), group B streptococcus (1), Meningococcus (1), Mycobacterium bovis (1), Aspergillus (1), coxsackie B (1), echovirus (1).

\# There were 16 organisms identified in 13 of the fatal cases. Two organisms were identified in three patients.

\#\# Of the 27 Legionella cases, 13 were $L$ pneumophilia, six $L$ micdadei, two $L$ longbeachae, two $L$ dumoffii, one $L$ jordanis, and three dual identifications. admission returned to a follow up clinic. Direct interview and, in seven cases, telephone interview revealed that $82(40 \%)$ had not returned to their usual level of activity. This was significantly associated with age $(p<0.001)$, co-morbidity $(p<0.001)$, blood urea level $(p<0.001)$, and severity of illness according to modified BTS criteria $(p=0.05)$. A follow up chest radiograph was obtained in $202(87 \%)$ cases. The pneumonic shadowing had completely resolved in 119 cases (59\%). Incomplete radiographic resolution was not associated with failure to regain normal activity levels.

Admission to the intensive care unit was required for eight patients, seven of whom required mechanical ventilation and four survived to hospital discharge.

\section{MORTALITY}

Twenty patients $(8 \%)$ died before hospital discharge and, of these, 13 died within 72 hours of admission. All but one were over 60 years of age and most $(90 \%)$ had a chronic underlying illness. Only four of the 20 patients who died were taking an antibiotic before admission. Pneumonia was considered to be the main cause of death in all cases.

A microbiological diagnosis was made in 13 of the 20 fatal cases with $S$ pneumoniae, accounting for six of the deaths. Two patients died from Legionella pneumonia. A post mortem diagnosis of invasive pulmonary aspergillosis was made in one patient who had been on oral corticosteroid treatment for severe COPD. Two patients died from Gram negative pneumonia (E coli and $P$ aeruginosa).

\section{Univariate analysis}

Twenty five of the 71 variables measured at admission were significantly $(p<0.05)$ associated with mortality (tables 2 and 3 ). These included age, a past medical history of COPD, 
Table 5 Multivariate analysis of factors associated with mortality

\begin{tabular}{|c|c|c|c|}
\hline Variable & Odds ratio & 95\% Confidence interval & p value \\
\hline \multicolumn{4}{|c|}{ Model A: stepwise logistic regression of all significant independent variables } \\
\hline Age $>65$ years & 21.6 & $(1.6$ to 287.8$)$ & 0.020 \\
\hline $\mathrm{PaO}_{2}<7.3 \mathrm{kPa}$ & 3.33 & $(1.0$ to 10.0$)$ & 0.049 \\
\hline AST $>57 \mathrm{mmol} / \mathrm{l}$ & 13.4 & (3.1 to 57.6$)$ & 0.001 \\
\hline Reduced peripheral perfusion & 10.5 & (2.6 to 41.7$)$ & 0.001 \\
\hline Respiratory rate $\geq 30 / \mathrm{min}$ & 4.3 & $(1.1$ to 16.5$)$ & 0.031 \\
\hline \multicolumn{4}{|c|}{ Model B: stepwise logistic regression with modified BTS score forced into the model } \\
\hline Modified BTS score & 9.4 & $(1.1$ to 82.3$)$ & 0.043 \\
\hline Age $>65$ years & 13.6 & (0.9 to 209.2$)$ & 0.061 \\
\hline $\mathrm{PaO}_{2}<7.3 \mathrm{kPa}$ & 5.0 & $(1.11$ to 10.0$)$ & 0.038 \\
\hline AST $>57 \mathrm{mmol} / 1$ & 10.1 & $(2.3$ to 43.2$)$ & 0.002 \\
\hline Reduced peripheral perfusion & 10.9 & $(2.7$ to 44.1$)$ & 0.001 \\
\hline
\end{tabular}

alcoholism, immune suppression, and chronic renal failure. The four variables (respiratory rate $\geq 30 / \mathrm{min}$, diastolic $\mathrm{BP} \leq 60 \mathrm{~mm} \mathrm{Hg}$, blood urea $>7.0 \mathrm{mmol} / \mathrm{l}$, and confusion) used in our modified severity score were each significantly associated with mortality. The physical sign most strongly correlated with fatal outcome was reduced peripheral perfusion which was noted in 11 of those who died but only 19 of the 227 who survived. Hypoxaemia $\left(\mathrm{PaO}_{2}\right.$ $<7.3 \mathrm{kPa}$ ) was recorded in nine of the patients who died and a raised AST level of $>57 \mathrm{mmol} /$ 1 in 11 . Bacteraemia was also significantly associated with mortality.

\section{Multivariate analysis}

Two hundred and twenty eight subjects (89\%) had sufficient data for multivariate analysis. Of the prognostic variables obtained on admission (table 2), age $>65$ years, $\mathrm{PaO}_{2}<7.3 \mathrm{kPa}$, AST $>57 \mathrm{mmol} / \mathrm{l}$, reduced peripheral perfusion, and a respiratory rate of $\geq 30 / \mathrm{min}$ were selected by the stepwise logistic regression analysis (table 5, model A). When the modified BTS criteria severity score was forced into the model, $\mathrm{PaO}_{2}$ $<7.3 \mathrm{kPa}$, AST $>57 \mathrm{mmol} / 1$, and reduced peripheral perfusion were selected (table 5 model B). With regard to mortality, the addition of variables selected in model $B$ reduced the sensitivity from 0.95 to 0.50 , but improved specificity from 0.71 to 0.95 and positive predictive value from 0.22 to 0.50 . Further modelling was performed to assess the potential value of adding $\mathrm{PaO}_{2}<7.3 \mathrm{kPa}$ to the modified rule or incorporating this variable into the rule itself. In both instances sensitivity was reduced but specificity improved. In the presence of a positive modified rule and a $\mathrm{PaO}_{2}$ of $<7.3 \mathrm{kPa}$, specificity for predicting mortality was 0.95 .

\section{SEVERITY ASSESSMENT}

When the severity assessment performed by the clinical teams was compared with the severity assessment based on modified BTS criteria there was an apparent underestimation of severity by the clinical teams in $47(21 \%)$ cases. If two or more of the variables used in the modified BTS rule (tachypnoea, diastolic hypotension, raised urea, or confusion) were present on admission there was a 36 -fold increased risk of death (table 6). This rule identified 19 out of the 20 patients who died as having severe pneumonia while the clinical teams identified 12 of 19 who died as severe, five as moderate, and two as mild. As a predictor of mortality the rule had a sensitivity of 0.95 , specificity 0.71 , positive predictive value 0.22 , and negative predictive value 0.99 (table 6 ). This compares favourably with the BTS rule 1 which had a sensitivity of 0.90 and specificity of 0.76 .

Six of the eight patients who required admission to the intensive care unit fulfilled the severity criteria, but only three were considered to have severe pneumonia by the clinical teams. As a predictor of mortality or the need for ICU admission the severity rule had a sensitivity of 0.88 , specificity 0.72 , positive predictive value 0.26 , and negative predictive value 0.98 .

Although we did not instruct the clinical teams as to what criteria to use in their severity assessment, they appeared to classify the patients' illness as severe when there was evidence of renal impairment, acidosis and signs of hypovolaemia, but did not seem to recognise the significance of a raised respiratory rate as an indication of life threatening pneumonia.

\section{INITIAL TREATMENT}

Antibiotics were given in 253 cases (99\%). Treatment during the 12 hours following admission was with a single agent in 224 cases $(89 \%)$, two in $28(11 \%)$, and three in one case. At least one antibiotic was given by the intravenous route in 200 cases $(79 \%)$. The most frequently prescribed antibiotics were amoxycillin-clavulanate in 99 (44\%), erythromycin in $48(21 \%)$, amoxycillin in $24(11 \%)$, cefuroxime in $25(11 \%)$, and benzyl penicillin in $21(9 \%)$. A single antibiotic was given as initial treatment to 21 of the 25 patients who died or required admission to the intensive care unit and was given by the intravenous route in 20. Antibiotic therapy was subsequently changed to a broader spectrum regimen including two antibiotics in seven of those who died. Most of the patients $(71 \%)$ classified as severe $(n=41)$ by the clinical teams were initially given a single antibiotic.

Intravenous fluids were given during the first 24 hours following admission in $42 \%$ of cases including 12 of the 20 patients who died. In

Table 6 Severity assessment: analysis of ability to predict mortality

\begin{tabular}{lllllll}
\hline Severity assessment & $n$ & $R R(95 \%$ CI $)$ & Sensitivity & Specificity & $P P V$ & NPV \\
\hline BTS rule 1 & 252 & $22.1(5.3$ to 92.7$)$ & 0.90 & 0.76 & 0.25 & 0.99 \\
BTS rule 2 & 255 & $9.9(4.2$ to 23.5) & 0.65 & 0.88 & 0.33 & 0.97 \\
BTS rule 3 & 239 & $9.1(3.8$ to 21.5) & 0.63 & 0.88 & 0.32 & 0.97 \\
Clinical assessment (severe) & 227 & $7.8(3.3$ to 18.5) & 0.63 & 0.86 & 0.29 & 0.96 \\
Modified BTS rule & 251 & $36.5(5.0$ to 268) & 0.95 & 0.71 & 0.22 & 0.99 \\
\hline
\end{tabular}

$R R=$ relative ratio; $P P V=$ positive predictive value $N P V=$ negative predictive value. 
the eight patients who died and in whom intravenous fluids were not given, signs suggestive of hypovolaemia (low JVP and/or reduced peripheral perfusion) were present in five.

DURATION OF HOSPITAL STAY

The mean duration of hospital stay was 8.5 days (range $1-60)$ and was longer $(p<0.001)$ in the presence of co-morbidity. A positive modified BTS rule was associated with a longer duration of stay $(p<0.001)$. Pneumonia due to Staphylococcus or Legionella resulted in the longest duration of stay (mean 15.4 days and 13.4 days, respectively) and that due to $\mathrm{Myco-}$ plasma the shortest (mean of 4.9 days).

\section{Discussion}

In this 12 month study of 255 patients with community acquired pneumonia a microbiological diagnosis was achieved in $71 \%$ and the mortality rate was $8 \%$. We have shown that a severity assessment based on prognostic variables available at the time of admission identifies a subgroup of patients at increased risk of admission to the intensive care unit or death from community acquired pneumonia. A positive modified BTS rule was associated with a 36-fold increased risk of death. The sensitivity (0.95) and positive predictive value $(0.22)$ of this rule in our cohort was similar to that found in the BTS study in which prognostic variables were obtained either at admission or during the hospital stay. ${ }^{1}$ Our study population was less restrictive than that reported by the BTS as it included older patients and had a greater proportion with underlying chronic illnesses. ${ }^{1}$ The severity criteria were readily applied at admission and are applicable to an unselected population of patients presenting to the general medical services of a large community hospital.

Univariate analysis identified 25 admission variables as predictors of mortality. These included the four variables (tachypnoea, diastolic hypotension, raised urea, and confusion) we selected for our severity rule. However, only tachypnoea remained as an independent predictor of mortality in the stepwise logistic regression (model A). According to this model, age $>65$ years, respiratory rate $\geq 30 / \mathrm{min}$, reduced peripheral perfusion, and AST $>57 \mathrm{mmol} / 1$ were independently predictive of mortality. This is likely to be due to differences between our population and the population from which the prognostic variables were originally derived, the most notable being advanced age which has been reported as an independent predictor of mortality by others. ${ }^{1415}$

The normal range for serum urea is increased in the elderly ${ }^{16}$ which may explain why 66 of 81 patients in our study who were over the age of 74 years had a blood urea concentration of $>7.0 \mathrm{mmol} / \mathrm{l}$ and why a raised urea was not independently predictive of mortality. Similarly, the presence of confusion was not independently predictive of mortality which may have been related to the prevalence of cognitive impairment in this older population. In our study all 13 patients with a previous history of dementia were over 74 years of age. Of these, two died and 11 survived.

A raised AST concentration ( $>57 \mathrm{mmol} / \mathrm{l}$ ) was an independent predictor of mortality. Previous studies have identified raised liver enzymes to be an independent predictor of prolonged hospital stay but not mortality. ${ }^{1}$ Elevation of liver enzymes in the setting of community acquired pneumonia is likely to reflect impaired hepatic perfusion in the unwell septic patient.

We have shown that reduced peripheral perfusion is an independent predictor of mortality in community acquired pneumonia. Although there is likely to be interobserver variability in the interpretation of this sign, in our institution it specifically implies cool peripheries with reduced capillary return on blanching the pulp of the digit. This valuable sign needs greater emphasis as an indicator of severe community acquired pneumonia.

Co-morbidity, particularly pulmonary and cardiac disease, was present in many of our patients and was significantly associated with a poor outcome. Brancati et al found co-morbidity to be a more important predictor of mortality than advanced age with respect to both hospital and long term mortality. ${ }^{10}$ Analysis of our population using the same comorbidity classification showed age alone to be a more important predictor of mortality. The difference is likely to be due to the populations studied. The cohort reported by Brancati et al had a much higher proportion of younger patients (18-44 years) with severe co-morbidity including HIV related disease and cancer, ${ }^{10}$ whereas our cohort was more representative of a general medical population.

The severity rule identified a subgroup of patients at increased risk of death or admission to the intensive care unit. Nineteen of the 20 patients who died had a positive rule giving a high sensitivity (0.95). The only fatal case in which the rule was not positive on admission was an elderly woman with bacteraemic pneumococcal pneumonia. Initially the only adverse prognostic feature was a raised urea level, but she rapidly deteriorated on the third day developing hypotension and tachypnoea before death.

The main limitation of the severity rule relates to its specificity which was 0.71 and positive predictive value which was 0.22 . In an attempt to improve the accuracy of the severity rule a second stepwise logistic regression model was applied (model B, table 5) in which additional variables (raised AST, reduced peripheral perfusion, and $\mathrm{PaO}_{2}<7.3 \mathrm{kPa}$ ) were selected. The addition of these variables improved the positive predictive value for mortality to 0.50 and the specificity to 0.95 but significantly reduced sensitivity to 0.50 . Thus, this model appeared to trade specificity (prediction of survival) for sensitivity (prediction of mortality). We regard the more sensitive rule as having greater value clinically and in this regard our modified rule performed better than any of the BTS rules. Furthermore, all of the 
relevant variables can be assessed on admission allowing the immediate identification of those at risk of a fatal outcome.

The range of causative organisms identified in this study was similar to that found elsewhere, although there are some differences in the relative proportions. As in most other studies, $S$ pneumoniae was the most common microorganism identified (39\%). ${ }^{18}$ M pneumoniae was a common diagnosis (16\%), particularly in younger patients. The high incidence was presumably because the study was done during a cyclical epidemic. ${ }^{17} \mathrm{C}$ pneumoniae was infrequent at $3 \%$ which is less than the commonly quoted range (6-10\%). ${ }^{18} \mathrm{~A}$ diagnosis of $\mathrm{Le}$ gionella infection was relatively common at $11 \%$. Most studies report figures of up to $6 \%$ but there is a wide range $(1-27 \%) .{ }^{8151920}$ Our high rate may in part be due to the fact that particular attention was directed towards detection of Legionella species.

The application of the severity rule at admission in a general medical population reliably identified a subgroup of patients who were at increased risk of dying or admission to intensive care unit. The apparent underestimate of severity of community acquired pneumonia by the clinical teams appeared to be due to the lack of significance attached to tachypnoea as a severe prognostic sign. They did recognise features of shock. Other studies have shown that recognition of life threatening community acquired pneumonia by clinical staff is often delayed, ${ }^{21}$ however it remains unclear whether treatment protocols based on these rules will influence outcome. Some have suggested that death from pneumonia is predetermined and that admission to intensive care merely prolongs the interval before death. ${ }^{22}$ However, we contend, as others have done, that identification of a high risk group and the application of optimal care for these patients has the potential to reduce mortality. ${ }^{23}$

The recommendations regarding initial antibiotic treatment from the BTS study ${ }^{1}$ which have been emphasised more recently in consensus guidelines ${ }^{23}$ state that, in cases of severe community acquired pneumonia, a regimen of two intravenous antibiotics should be started promptly. This strategy has been recommended because of the lack of specificity of clinical ${ }^{45}$ and radiographic ${ }^{67}$ features for particular organisms, and the need to provide adequate antibiotic therapy while awaiting the results of microbiological investigations. We found that most patients were initially treated with a single agent, including many of those with severe pneumonia. Since $23 \%$ of those patients with severe pneumonia and a microbiological diagnosis had either Legionella or Mycoplasma infection (including some dual infections), we support the use of an empirical regimen of an intravenous macrolide plus a broad spectrum beta-lactam antibiotic. Antibiotic therapy should be instituted without delay, particularly in those patients meeting the criteria for severe pneumonia. $^{23}$
In conclusion, we have completed a large study of community acquired pneumonia in patients presenting to a community hospital in New Zealand and found the range of causative organisms to be similar to those reported elsewhere with the exception of Legionella pneumonia which was more common. The application on admission of a simple modification of the BTS criteria for severity proved a robust tool for the immediate identification of those most at risk of admission to the intensive care unit or death.

The authors gratefully acknowledge assistance from many staff at Canterbury Health particularly the physiotherapists, residen doctors, nurses, laboratory staff and medical records personnel. Dr Frans Hilbink assisted with $Q$ fever diagnosis. Sally Bagley prepared the manuscript.

Funding support was provided by The Canterbury Medical Research Foundation and The Canterbury Respiratory Research Trust. Abbott Pharmaceuticals (NZ) provided funding for the Legionella laboratory work.

1 Research Committee of the British Thoracic Society and the Public Health Laboratory Service. Community acquired pneumonia in adults in British hospitals in 1982-83. a survey of aetiology, mortality, prognostic factors and outcome. Q f Med 1987;62:195-220.

2 British Thoracic Society. Guidelines for the management of community-acquired pneumonia in adults admitted to hospital. Br F Hosp Med 1993;49:346-50.

3 American Thoracic Society. Guidelines for the initial management of adults with community acquired pneumonia: agement of adults with community acquired pneumonia therapy. Am Rev Respir Dis 1993;148:1418-26.

4 Woodhead MA oodhead MA, MacFarlane JT. Comparative clinical and laboratory features of legionella with pneumococcal and

mycoplasma pneumonias. Br f Dis Chest 1987;81:133-9. diction of microbial aetiology at admission to hospital for pneumonia from the presenting clinical features. Thorax pneumonia from

6 MacFarlane JT, Miller AC, Roderick Smith WH, Morris $\mathrm{AH}$, Rose DH. Comparative radiographic features of community acquired legionnaires' disease, pneumococcal pneumonia, mycoplasma pneumonia, and psittacosis. Thorax 1984;39:28-33.

7 Tew J, Calenoff L, Berlin BS. Bacterial or nonbacterial pneumonia: accuracy of radiographic diagnosis. Radiology 1977;124:607-12.

8 Karalus NC, Cursons RT, Leng RA, Mahood CB, Rothwell RPG, Hancock B, et al. Community acquired pneumonia: aetiology and prognostic index evaluation. Thorax 1991 46:413-8.

9 Farr BM, Sloman AJ, Fisch MJ. Predicting death in patients hospitalised for community acquired pneumonia. Ann hospitalised for community $1991 ; 115: 428-36$.
Intern

10 Brancati FL, Chow JW, Wagener MM, Vacarello SJ, Yu VL. Is pneumonia really the old man's friend? Two year prognosis after community acquired pneumonia. Lancet prognosis after

11 Rosner BA. In: Fundamentals of biostatistics. Boston: Duxbury Press, 1982:417.

12 Siegel S. In: Nonparametric statistics for the behavioural sciences. New York: McGraw-Hill, 1956:184-94.

13 Hodkinson HM. Mental impairment in the elderly. $f R$ Coll Phys Lond 1973;7:305-17.

14 Bohte R, van Furth R, van den Broek PJ. Aetiology of community-acquired pneumonia: a prospective study among adults requiring admission to hospital. Thorax 1995;50:543-7.

15 Lim I, Shaw DR, Stanley DP, Lumb R, McLennan G. A prospective hospital study of the aetiology of communityacquired pneumonia. Med f Aust 1989;151:87-91.

16 Leask RGS, Andrews GR, Caird FI. Normal values for sixteen blood constitutents in the elderly. Age Ageing 1973 2:14-23.

17 Ghosh K, Clements GB. Surveillance of Mycoplasma pneumoniae infections in Scotland 1986-1991. F Infect 1992; 25:221-7

18 Marrie TJ. Chlamydia pneumoniae - editorial. Thorax 1993;

19 Fang GD, Fine M, Orloff J, Arisumi D, Yu VL, Kapoor W, et al. New and emerging etiologies for community-acquired pneumonia with implications for therapy: a prospective
multi-centre study of 359 cases. Medicine $1990 ; 69: 307-16$.

20 Roig J, Domingo C, Morera J. Reviews: Legionnaires' disease. Chest 1994;105:1817-25.

21 Rogers RM, Weiler C, Ruppenthal B. Impact of the respiratory intensive care unit on survival of patients with piratory intensive care unit on survival of pati

22 Hook EW, Horton CA, Schaberg DR. Failure of intensive care unit support to influence mortality from pneucare unit support to influence mortality from

23 Ewig S, Bauer T, Hasper E, Pizzulli L, Kubini R, Luderitz B. Prognostic analysis and predictive rule for outcome B. Prognostic analysis and predictive rule for outcome Respir 71 1995;8:392-7. 